\title{
Infarto segmentario de testículo
}

\author{
L. Ripa Saldías, R. Guarch Troyas *, A. Hualde Alfaro, A. de Pablo Cárdenas, M. Ruiz Ramo, \\ M. Pinós Paul
}

Servicio de Urología y *Servicio de Anatomía Patológica. Hospital Virgen de Camino. Pamplona.

Actas Urol Esp 2006; 30 (2); 227-230

\section{RESUMEN \\ INFARTO SEGMENTARIO DE TESTÍCULO}

Presentamos el caso de un varón de 47 años diagnosticado meses antes de hidrocele izquierdo que en estudio sonográfico reciente, realizado por dolorimiento testicular, presentaba lesión sólida nodular sugestiva de neoplasia testicular izquierda. Fue sometido a orquiectomía radical. El análisis de la pieza quirúrgica demostró la presencia de infarto segmentario con ausencia de tumor. Revisamos la bibliografia sobre el tema.

Palabras clave: Testículo. Infarto segmentario.

\section{ABSTRACT}

SEGMENTAL TESTICULAR INFARCTION

We report the case of a 47 years old man previously diagnosed of left hidrocele. After having a recent mild left testicular pain, an ultrasonografic study revealed a solid hipoecoic testicular lesion rounded by a big hidrocele, suggesting a testicular neoplasm. Radical inguinal orchiectomy was made and pathologic study showed segmental testicular infarction. No malignancy was found. We review the literature of the topic.

Keywords: Testis. Segmental infarction.

$\mathrm{E}$ infarto segmentario de testículo es una entidad infrecuente; de etiología generalmente idiopática. Se manifiesta como dolor escrotal agudo o subagudo. El diagnóstico se basa en la sospecha clínica y las pruebas de imagen, fundamentalmente Eco-doppler y RMN, que deben sugerir esta patología y permitir un tratamiento conservador con ciertas garantías. Todavía es habitual el diagnóstico a partir de piezas de orquiectomía por sospecha de tumor testicular.

\section{CASO CLÍNICO}

Paciente de 47 años con antecedentes de ulcus gástrico, fumador de 10 cigarrillos/día, vasectomizado, que consulta por aumento moderado de volumen escrotal izquierdo desde hace años pero con incremento durante el último mes, acompañado de molestias sordas, sin dolor agudo. No sintomas miccionales ni fiebre.
A la exploración física destaca la presencia de hidrocele de mediano tamaño que impide la exploración de testículo y epidídimo. Los análisis generales de sangre y orina fueron normales. Se realizó ecografía escrotal (Fig. 1) informada como imagen nodular intratesticular izquierda de bordes bien definidos, sugestiva de neoplasia testicular e hidrocele de contenido anecoico. Marcadores tumorales (AFP y $\beta-\mathrm{HCG}$ ) normales. Se practicó orquiectomía inguinal izquierda con colocación de prótesis testicular siliconada. Tras un postoperatorio inmediato normal se realizó TAC abdominal que fue normal. La pieza quirúrgica mostraba macroscópicamente una zona de testículo infartada alternando con otra aparentemente normal (Fig. 2), confirmando la presencia de infarto testicular en el estudio microscópico con ausencia de tumor. 


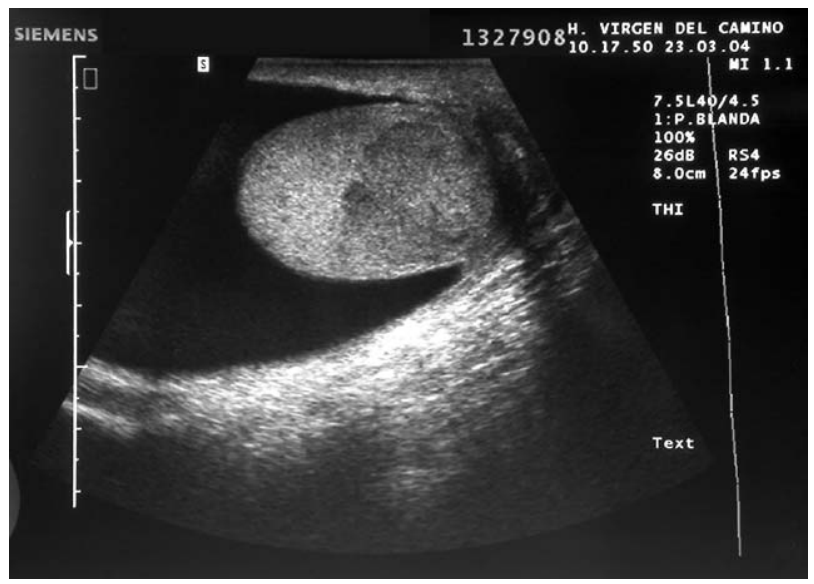

FIGURA 1: Imagen hipoecogénica intratesticular rodeada por hidrocele.

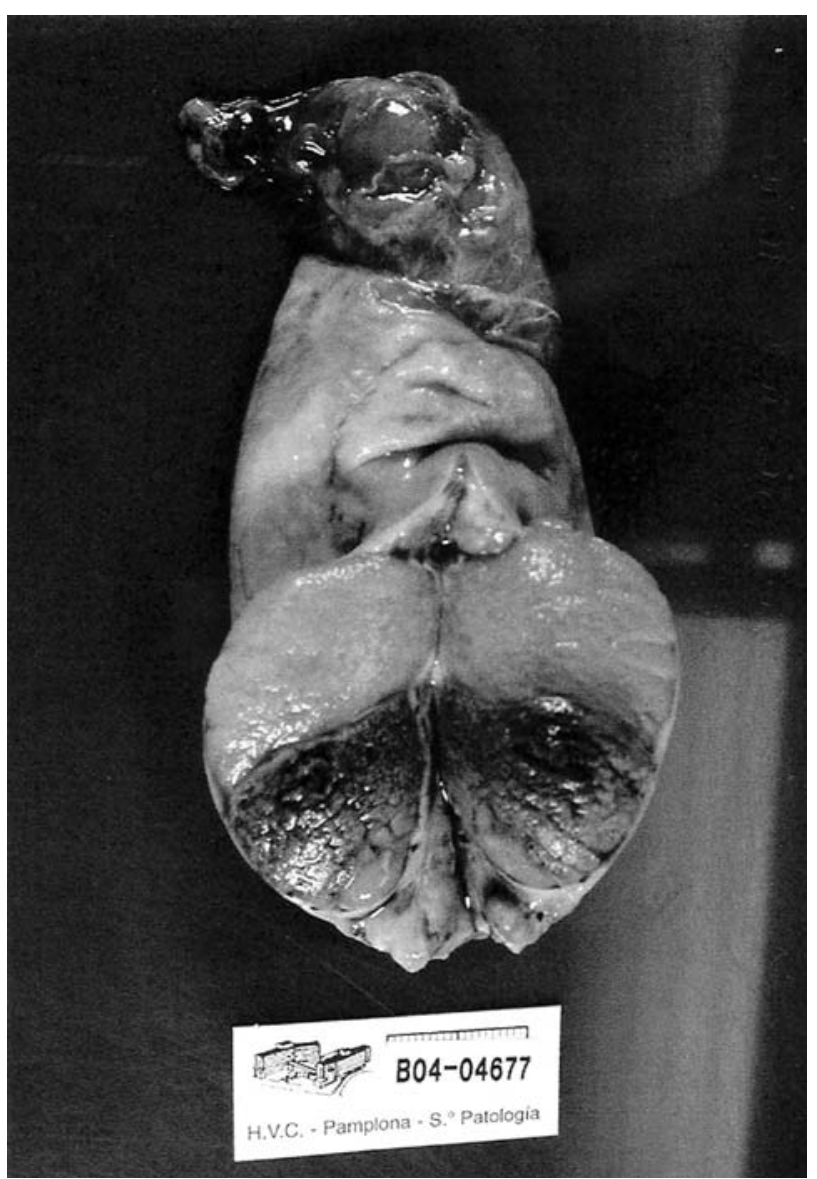

FIGURA 2: Sección de testículo izquierdo con área segmentaria infartada.

\section{DISCUSIŌN}

El infarto testicular global es un cuadro relativamente frecuente y generalmente secundario a torsión del cordón espermático aunque se ha atribuido a otras posibles causas como hernias incarceradas, epididimitis, etiología idiopática, etc.; sin embargo el infarto focal de testículo es una entidad infrecuente si nos basamos en publicaciones. Hasta 1996 sólo se habían descrito $12 \operatorname{casos}^{1}$ y en 2000 se añade un caso más a los 20 recogidos en la literatura ${ }^{2}$. En España destaca la publicación de Ruibal y cols ${ }^{3}$ que presentan dos casos y revisa otros cuatro más. El infarto segmentario puede presentarse a cualquier edad pero predomina en la edad media de la vida, habiéndose descrito un caso en anciano de 79 años ${ }^{4}$.

La etiología del infarto segmentario es frecuentemente idiopática aunque se han atribuido a múltiples causas como epididimitis, vasculitis, fibroplasia de la media de arteria espermática, poliarteritis nodosa, traumas (incluyendo cirugía laparoscópica de hernia inguinal) ${ }^{5}$, policitemia, grandes esfuerzos, anemia de células falciformes $^{6}$, trombosis arterial por déficit de proteína $\mathrm{S}^{7}$, embolia arterial espermática por émbolos de colesterol, tromboangeitis obliterante, torsión seguida de detorsión espontánea del cordón ${ }^{8}$, etc. Ameur et al. ${ }^{9}$ comunican un caso de infarto segmentario en un testículo ectópico inguinal sin evidencia de torsión ni otras causas. La clínica más frecuente es el dolor escrotal unilateral, en ocasiones localizado en fosa iliaca e irradiado a testículo. El dolor suele ser de intensidad variable, puede durar días o semanas y no se acompaña de síntomas miccionales.

La exploración física varía según la fase evolutiva pudiendo ser normal al inicio del cuadro doloroso o bien presentar signos inflamatorios locales o incluso palparse nódulo o zona indurada a nivel testicular.

La forma más frecuente de diagnóstico es por estudio histológico de piezas de orquiectomía radical realizadas por supuesto tumor o tras orquiepididimitis de evolución tórpida. Sin embargo en los últimos años no es infrecuente el diagnóstico de sospecha de infarto de forma preoperatoria basado en pruebas de imagen. La ultrasonografía con doppler y la resonancia magnética nuclear (RMN) pueden inducir a un alto índice de sospecha, si bien puede resultar difícil descartar categóricamente el tumor de testículo. Si consideramos esta posibilidad se puede optar por tratamiento conservador de la gónada, total o parcial. 
En ecografía testicular el dato más frecuente es la presencia de área hipoecogénica bien delimitada, en ocasiones de forma triangular con vértice en mediastino testicular, con signos de ausencia de vascularización en ecodopler-color ${ }^{3}$. El diagnóstico diferencial de estas áreas hipoecóicas hay que hacerlo con neoplasias, abscesos, hemorragias o infartos. Los tumores se presentan generalmente como áreas focales de variada ecogenicidad, sin poder diferenciar lesiones benignas de malignas; con eco doppler esas lesiones si son mayores de $16 \mathrm{~mm}$ se asocian con aumento y desorden de vascularización ${ }^{10}$, siendo por tanto fundamental identificar vascularización que permita diferenciar tumores de infartos. El infarto testicular tanto global como segmentario se caracteriza por área hipoecóica sin refuerzo posterior y pobreza o ausencia de flujo en doppler; no obstante tumores menores de 1,6 cm pueden presentar aspecto similar. Los hallazgos sonográficos en los infartos varían según la fase evolutiva del proceso ${ }^{11}$. Los abscesos o zonas de supuración se presentan como áreas hipo o anecoicas con anillo hipervascular alrededor de la lesión.

En RMN el patrón característico es una lesión con área central de baja intensidad y otra periférica de alta señal sugestivo de isquemia, aunque no se pueden descartar lesiones neoplásicas (sobre todo tumores menores de 1,6 cm). En un caso aportado por Kodama ${ }^{2}$ la $\mathrm{RMN}$ se realizó 5 días después del cuadro doloroso y apreciaron una masa bien circunscrita con intensidad media de señal en T1 y alta intensidad en T2. Tras administrar gadolinio la imagen presentaba un anillo de alta señal en T1. Las imágenes RMN también varían según el estadio evolutivo del infarto. Esta técnica puede suponer una ayuda en el diagnóstico de patologías testiculares aunque no siempre es posible excluir tumores o abscesos. Las nuevas técnicas de RMN podrán en el futuro reducir la frecuencia de exploraciones quirúrgicas de enfermedades benignas como el infarto testicular ${ }^{2}$.

El tratamiento más frecuentemente realizado ha sido la orquiectomía radical por supuesto tumor pero si se sospecha esta patología se debe proceder a resección testicular parcial precedida de biopsia intraoperatoria ${ }^{2,3,8,12}$. El tratamiento conservador del teste se debe reservar para casos en los que la historia, exploración y datos complementarios sugieran de una forma consistente la posibilidad de lesión benigna. Incluso en esos casos se puede recurrir a la vía inguinal, exploración de teste con clampaje de cordón y biopsia que confirme la lesión isquémica, no tumoral, de una forma categórica. En caso contrario se procederá a orquiectomía radical. Cuando se recurre a cirugía exploradora urgente por sospecha clinica de torsión, sin datos ultrasonográficos preoperatorios, y se evidencia lesión sugestiva de infarto segmentario puede realizarse exploración gonadal tras sección bivalva, como describen Costa et al. ${ }^{13}$ y practicar exéresis sólo de la lesión, una vez descartada la posibilidad de neoplasia.

En los últimos años se han publicado varios casos con alta sospecha diagnóstica de infarto testicular segmentario basándose en eco-doppler y/o RMN. No obstante se procedió a exploración quirúrgica practicándose orquiectomía ${ }^{14}$ o exploración de la gónada y tras comprobar la presencia de la zona focal isquémica se actuó de forma conservadora mediante exéresis de la zona lesionada y preservando la sana ${ }^{12}$. Otra opción de tratamiento conservador es la actitud expectante con controles seriados de Eco-doppler o RMN, cuando el grado de certeza diagnóstica es alto, pudiendo apreciarse la revascularización y reducción lesional ${ }^{15}$, evitándose así una cirugía.

\section{REFERENCIAS}

1. Baratelli, GM; Vischi, S.; Mandelli, PG; Gambetta, GL; Visetti, F; Sala, EA. Segmental hemorrhagic infarction of testicle. J.Urol. 1996, 156(4): 1442

2. Kodama K; Yotsuyanagi S; Fuse H; Hirano S; Kitagawa K; Masuda S. Magnetic resonance imaging to diagnose segmental testicular infarction. J.Urol. 2000, 163(3):910-911.

3. Ruibal M; Quintana JL; Fernandez G; Zungri E. Segmental Testicular Infarction. J.Urol.2003, 170(1): 187-188.

4. Nayal W; Brassett C; Singh L; Boyd PJR. Segmental testicular ischaemia mimicking testicular tumour. British Journal of urology 1996, 78(2):318-319.

5. Mincheff T; Bannister B; Zubel P. Focal testicular infarction from laparoscopic inguinal hernia repair. JSLS. 2002;6(3): 211-213.

6. Maomi Li, James Fogarty, Kathleen D Whitney and Peter Stone. Repeated testicular infarction in a patient with sickle cell disease: a possible mechanism for testicular failure. Urology, 2003, Case Report Abstracts.

7. Lee YL; Huang CN; Huang $\mathrm{CH}$. Testicular infarction associated with protein S deficiency. J.Urol. 2001, 165(4): 12201221 . 
8. Ledwidge ME; Lee DK; Winter TC; Uehling DT; Mitchell CC; Lee FT. Sonographic Diagnosis of Superior hemispheric testicular Infarction. AJR Am J Roentgenol. 2002 Sep; 179(3): 775-776.

9. Ameur A, Zarzur J, Albouzidi A, Lezrec M, Beddouch A, Idrissi AO. Testicular infarction without torsion in cryptorchism. (Abstract) Prog Urol. 2003; 13: 321-3

10. Sriprasad S.; Kooiman GG.; Muir GH; Sidhu PS. Acute segmental testicular infarction: differentiation from tumour using high frequency colour doppler ultrasound. Br J Radiol. 2001; 74(886):965-967.

11. Han DP; Dmochowski RR, Blasser MH; Auman JR. Segmental infarction of the testicle: Atypical presentation of a testicular mass. J.urol. 1994, 151(1):159-60.

12. Danon O; Morsli F.; Boukobza B.; Khuoy L.; Fretin J. Infarctus testiculaire segmentaire. La press Medical 2000, 29:1603.
13. Costa M; Calleja R; Ball RY; Burgess N. Segmental testicular infarction. BJU international 1999, 83(4):525.

14. Kramolowsky EV; Beauchamp RA; Milby WP. Color doppler ultrasound in testicular infarction. J.Urol 1993,150:972973.

15. Sentilhes L, Dunet F, Thoumas D, Khalaf A, Grise P, Pfister C. Segmental testicular infarction: diagnosis and strategy. Can J Urol. 2002;9(6):1698-701

Dr. Luis Ripa Saldías

E-mail: luiripasal@yahoo.es

(Trabajo recibido el 10 de mayo de 2005) 